\title{
Intracranial stimulation as an avoidance or escape response'
}

GORDON G. BALL AND DONALD W. ADAMS

STANFORD RESEARCH INSTITUTE, MENLO PARK, CALIFORNIA

\begin{abstract}
Rats approached intracranial stimulation (ICS) in a T-maze under massed trials, but avoided it when the trials were spaced $30 \mathrm{~min}$. apart. In a second experiment, rats approached ICS in a modified Skinner box on an FI schedule of $15 \mathrm{sec} .$, but avoided it when the FI schedule was $5 \mathrm{~min}$. The results are interpreted in terms of ICS being an avoidance or escape response from noxious after-effects of the previous ICS.
\end{abstract}

\section{Introduetion}

In their original study of the effects of ICS in rats, Olds \& Milner (1954) proposed that the phenomenon was related to positive reinforcement mechanisms. They rejected, on observational grounds, the possibility that it could be caused by the first stimulus's noxious after-effects, which are reduced by a second stimulus. The two hypotheses can be stated as follows:

1. The ICS simultaneously activates a basic reward and a basic drive system (Olds, 1962; Deutsch \& Howarth, 1963). The reinforcement is contingent upon ICS, but the drive decays to zero as a function of time from the previous ICS (Deutsch, 1964).

2. The ICS reinforces the animal by reducing negative stimuli produced by the after-effects of the preceding ICS. These negative after-effects disappear completely as a function of time from the last ICS.

Both hypotheses predict consistent bar-pressing behavior in a Skinner box under conditions on $100 \%$ ICS. However, they differ in predicting an animal's performance in an ICS situation several minutes after the last ICS.

1. The hedonic viewpoint, as expressed by Olds (1962), holds that an animal would respond positively due to secondary cues associated with the situation. Deutsch et al (1964), however, predicted that animals would be indifferent to the situation, due to the absence of drive.

2. According to the avoidance hypothesis, ICS would lose its reinforcing power once the previous aftereffects had decayed. Since a further stimulus would produce additional negative after-effects, animals should learn to avoid it.

These predictions were tested in two experiments using long versus short time intervals between ICSs. A T-maze was used for one test, a modified Skinner box for the other.

\section{Method}

Monopolar electrodes were implanted in the posterior hypothalamus of adult male Long-Evans rats. First, all animals were tested in an open-field in which they were given ICS whenever they approached a particular area. The ICS, a 2 sec. train of dc pulses of $0.1-\mathrm{msec}$. duration at the rate of $100 \mathrm{pps}$, was delivered through an isolation transformer. Threshold voltages which kept each animal in the prescribed area were determined, and were used throughout the behavioral tests.

Twenty animals showing consistent responsiveness were selected and divided into four groups. At the end of behavioral testing, the animals were sacrificed and the electrode tips were found to be distributed close to, or in, the median forebrain bundle (MFB) in an anterior-posterior plane from A 3.8 to A 2.6, using deGroot's coordinates.

\section{Experiment 1}

A simple T-maze with an elevated runway ( 12 in $\times 2$ in) was used. The runway opened directly onto high-walled yellow goal boxes (10 in $\times 3$ in). A black rubber, 2-in stopper (stimulus object), randomly alternated from one goal to the other between trials, served as a visual cue for ICS.

Massed Group $(N=5)$. Each animal ran 120 trials in the T-maze. Brain stimulation was given when $S$ entered the goal box containing the rubber stopper, but not when $S$ entered the other goal box. After $S$ had been in the goal box for 20 sec., it was returned to the start.

Spaced Group $(N=5)$. Ss ran as in the massed group except that they were returned to their home cages for a minimum of $30 \mathrm{~min}$. between trials. Each $S$ ran 15 trials a day for a total of 120 trials.

\section{Results}

Figure 1 shows that the massed group approached the stimulus object more and more often, whereas the spaced group showed increasing avoidance. A t-test on the last 20 trials showed each group to be significantly

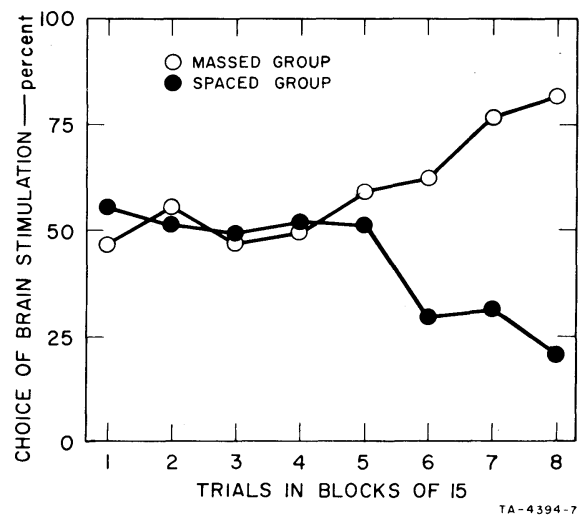

Fig. 1. Per cent choice of brain stimulation side in the $T$-maze during 120 trials. 
different from chance $(p<0.005)$. It should be emphasized that every animal in the massed group showed a tendency to approach, while every animal in the spaced group showed a tendency to avoid the stimulus object.

\section{Experiment II}

This experiment was run to test the hypothesis in a different situation and to eliminate any experimenter bias that might have influenced the $T$-maze results.

One half of the floor of a Skinner box was painted black and the other half yellow. The floor was modified so that the animal had only to step onto the black half of the floor to obtain ICS. ICS was delivered if both of two conditions prevailed: (1) the animal had to be on the black side, and (2) a predetermined interval (FI) must have elapsed since the last ICS. Crossing to black after the FI had elapsed also produced ICS and began the next FI cycle.

Massed Group $(N=5)$. Animals ran seven daily sessions of 3 $\mathrm{min}$. each, with an FI of $15 \mathrm{sec}$. Sessions began when an animal was dropped onto the black side of the floor, and thereby given immediate ICS. A minimum of one and a maximum of 12 ICSs were possible within each 3-min. session.

Spaced Group $(N=5)$. The procedure was identical to that described for the massed group, except that the $\mathrm{FI}$ was $5 \mathrm{~min}$. and the session length, $1 \mathrm{hr}$.

\section{Results}

Two measures were recorded in the Skinner box: the number of ICSs and the proportion of time spent on the black (ICS) side during each session. Figure $2 \mathrm{a}$ shows the proportion of time spent on the black side of the floor. During the last two sessions the massed
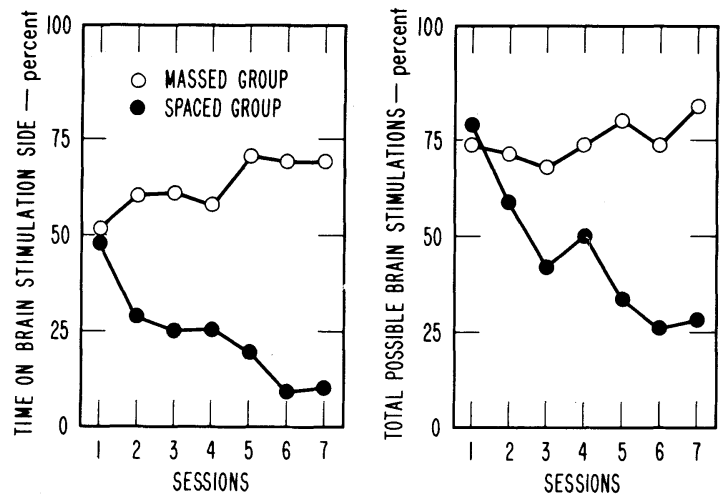

Fig. 2. Left: per cent of time spent on the side producing brain stimulation. Right: per cent received of total possible brain stimulations in the modified Skinner box. group spent a significantly high proportion of time on the black side $(p<0.02)$, while the spaced group showed a marked reduction $(p<0.001)$. Figure $2 b$ shows that the massed group received a large proportion of the total ICSs during the first session. This proportion remained consistently high from session to session. However, the spaced group showed a rapid drop. A t-test between the scores of the two groups during the last two sessions was significant $(p<0.01)$ 。

\section{Diseussion}

Two conclusions can be drawn from the results.

1. If an animal approaches ICS under massed conditions, but avoids it under spaced, the ICS alone cannot be regarded as a sufficient condition for positive reinforcement.

2. The avoidance of ICS in spaced, but not massed, conditions indicates an aversive event occurring some time after a brain stimulation.

If it is assumed that stimulation to the brain can reduce the aversive after-effect, the data are easily explained: animals in the massed condition are reinforced by escaping the after-effects with another ICS; animals in the spaced condition are reinforced, once the aftereffects have dissipated, by avoiding the situation which produces aversive after-effects.

Thus, the results agree with an explanation in terms of avoidance or escape behavior and are incompatible with a hedonic interpretation.

\section{References}

Deutsch, J. A., Adams, D. W., \& Metzner, R. J. Choice of intracranial stimulation as a function of delay between stimulations and strength of competing drives. J. comp. physiol. Psychol. $1964,57,241-243$.

Deutsch, J. A., \& Howarth, C. I. Some tests of a theory of intracranial self-stimulation. Psychol. Rev., 1963, 70, 444-460.

deGroot, J. The rat forebrain in stereotaxic coordinates. Verhandelingen der Kon. Ned. Kademie von Wetenschappen, a.f.d. Natuurkunde. Second Series, 52(4). Amsterdam: North-Holland, 1959.

Olds, J. Hypothalamic substrates of reward. Physiol. Rev., 1962 $42, \quad 554-604$.

Olds, J., \& Milner, P. Positive reinforcement produced by electrical stimulation of septal area and other regions of the rat brain. J. comp. physiol. Psychol., 1954, 47, 419-427.

\section{Note}

1. This research was supported by General Research Support grant No. 1S01 FR-05522-03-5 from the National Institutes of Health to Stanford Research Institute. 